\title{
Perception and experiences regarding COVID-19 pandemic among urban young adults in Bangladesh: a mixed-method study
}

\author{
Sabbir Pervez ${ }^{1} \cdot$ Shabnam Naher ${ }^{2} \cdot$ Mamun Ur Rashid Pranta $^{2} \cdot$ Rajon Banik $^{2}$ (I) $\cdot$ Quazi Maksudur Rahman $^{2}$ \\ Received: 27 August 2020 / Accepted: 18 May 2021 / Published online: 28 June 2021 \\ (C) The Author(s), under exclusive licence to Springer-Verlag GmbH Germany, part of Springer Nature 2021
}

\begin{abstract}
Aim This study aimed at exploring the perception and experiences with regard to the COVID-19 pandemic among Bangladeshi urban young adults.

Subject and methods Using a mixed-method approach, an online cross-sectional survey among 315 participants and in-depth interviews (IDI) among 20 young adults were conducted from May 1 to May 25, 2020. Descriptive statistics and chi-square tests were performed for quantitative data, along with the thematic analysis for qualitative data.

Results The mean $( \pm \mathrm{SD})$ age of the participants was $26.54( \pm 3.05)$, and the majority were male $(54.9 \%)$. About $81.6 \%$ of the participants reported COVID-19 as a viral disease, transmitted through droplets of sneezing and coughing, and close contact with another person (90.8\%). Nearly $40 \%$ of participants reported news channels as a reliable source of information for COVID-19. Participants who were male were less likely to be aware than females in terms of mode of transmission of COVID-19 such as going outside of the home ( $82.7 \%$ male vs $90.8 \%$ female; $p<0.05)$. Male participants thought they were perfectly healthy and more reluctant to agree with maintaining social distance compared to female participants $(72.8 \%$ male vs $90.1 \%$ female; $p<0.001$ ). Participant's satisfaction level with services provided by the government was also significantly different and higher among females than male participants $(39.9 \%$ male vs $53.5 \%$ female; $p<0.05)$. The majority of the participants reported suffering due to financial uncertainty, psychological distress, and inadequate health facilities. Dissatisfaction was reported with the existing health services as creating several misconceptions, lacking testing facilities, and debasement by the health professionals.

Conclusion This study found a better perception regarding COVID-19 among the young adults, but they had poor preventive practices. Health education intervention with the rapid response should be implemented targeting this vulnerable group to improve their preventive practices.
\end{abstract}

Keywords COVID-19 $\cdot$ Perception $\cdot$ Experiences $\cdot$ Young adults $\cdot$ Bangladesh

Shabnam Naher

shabnam@juniv.edu

Rajon Banik

rajonbanik.phi.ju@gmail.com

Sabbir Pervez

sabbirpervez@gmail.com

Mamun Ur Rashid Pranta

pranto.phiju@gmail.com

Quazi Maksudur Rahman

qmrmaruf45@gmail.com

1 Department of Statistics, Jahangirnagar University, Savar, Dhaka 1342, Bangladesh

2 Department of Public Health and Informatics, Jahangirnagar University, Savar, Dhaka 1342, Bangladesh

\section{Introduction}

Worldwide, the novel coronavirus (COVID-19) is a significant public health concern that draws international attention due to its emergence (Wang et al. 2020). The recent appearance of COVID-19 is caused by a new coronavirus which is known as severe acute respiratory syndrome coronavirus 2 (SARS-CoV-2), and the symptoms include fever, shortness of breath, cough, fatigue, and diarrhea. It is assumed that it has started to spread through zoonotic interaction - that is, human and animal interaction. Now it is spreading through human-to-human interaction by direct contact as well as droplets generated by an infected person's cough or sneezing (Huang et al. 2020). World Health Organization (WHO) reported that the pre-eminent way to prevent COVID-19 is to 
slow down the transmission of COVID-19; by suggesting people wash their hands with soap, use hand sanitizers frequently, avoid touching the face, nose, mouth, and eyes with washed hands, staying home, and maintaining social distance to being protected from the infection (WHO 2020a).

Now, this outbreak places a mental toll on young adults as it shapes values and harms health drastically. It is the latest calamity for a generation that has experienced life-altering disruptions (Polakovic 2020). The first case of COVID-19 officially recorded in Bangladesh on March 8, 2020 (Banik et al. 2020), and since then the total number of confirmed cases spiked swiftly, and recorded approximately 299,628 infected patients and 4028 deaths, with the current mortality rate being higher than $6 \%$ as a result of this disease up to August 25, 2020 (Corona Tracker 2020). People aged between 21 and 40 accounts for $55 \%$ of the total positive cases, which is higher than other age groups. It is alarming that approximately $50 \%$ of infected individuals in Bangladesh are less than 40 years of age (IEDCR 2020). Despite widespread concern regarding COVID-19, no antiviral medicines have yet been recommended for this treatment (Gudi et al. 2020). Even for receiving telemedicine services during this pandemic there exist some barriers (Rahman et al. 2020). Shreds of evidence showed that perception towards COVID-19 in Bangladesh has been reported as positive, although it is noteworthy that a portion of individuals also expressed negative attitudes towards this virus (Farhana 2020; Hossain et al. 2020). In earlier studies, almost $18.3 \%$ of participants expressed a negative attitude towards the statement of washing hands with soap and water can help to prevent COVID-19 transmission, which is very alarming in the forthcoming days (Wadood et al. 2020). Another study conducted among students in Bangladesh reported that nearly half of the study participants thought they were not or not at all exposed to COVID-19 and only a smaller portion of them was moderately worried about its infectiousness and also its consequences, and slightly fearful of it. These students also felt that the COVID-19 outbreak affected their daily as well as their family's daily routine, study, field works, financial issues, and leisure time (Wadood et al. 2020).

As in many countries in the world, Bangladesh is also trying to expand its controlling mechanisms by imposing countrywide lockdown and urging people to maintain the preventive guidelines instructed by WHO. A significant number of studies already have been reported on knowledge and perception regarding COVID-19 to examine the numerical situation of this virus in the prospect of this global crisis (Banik et al. 2021; Farhana 2020; Islam et al. 2020; Rahman and Sathi 2020). Apart from this, as of the date of writing this paper, limited studies have been reported on how people perceive qualitatively; that is, their behavioral changes, their attitude towards COVID-19, their vulnerability and sufferings, social panic, and how it impacts their everyday life. When it comes to a special group such as the urban young adults in Bangladesh, they are not giving attention, which is very alarming. Although the age range of young adults is culturespecific, in this study we assume the age range of $18-35$ as young adults (Ministry of Youth and Sports 2017; WalkerHarding et al. 2017). For this reason, to validate these existing phenomena, in-detail observation, and understanding about urban young adults, it is highly necessary to examine their perceptions with regard to COVID-19. It will further help to take appropriate preventive measures against COVID-19 as well as reducing the disease outbreak among young adults in Bangladesh.

\section{Methods}

\section{Research design}

A mixed-method design was used to collect data, which included the experiences of an urban young adult in regard to the perception of the COVID-19 outbreak in Bangladesh. This method was applied to catch diverse perspectives on the social world and social situations of people (Gilbert 2006). In this mixed-method design, the quantitative investigation was performed to assist in explaining as well as elaborating upon the findings of the qualitative data (phase II).

\section{Study design and participants}

A cross-sectional study was carried out from May 1 to May 25, 2020, among young adults in some selected urban areas of Bangladesh. The inclusion criteria for participating in the study were: i) individuals currently living in urban areas, ii) young adults aged 18 years or older, iii) users of social media (e.g. Facebook, WhatsApp), and iv) those who exhibited their willingness to participate in the online survey. The exclusion criteria included participants who were unable to participate via online interviews, and/or living outside an urban area.

\section{Quantitative interview outline and data collection procedure (phase I)}

A total of 315 young adults with an age ranging from 18 to 35 years were selected, and data were collected via a webbased survey through a convenient sampling technique. By preparing a consent form, an online semi-structured questionnaire was developed by the researchers after reviewing the available relevant literature. Further, it was entered in a questionnaire format by using a Google form. After taking verbal and written consent and communicating the purpose and significance of the study to the participants, the questionnaire was sent to the participants through email, Facebook 
Messenger, Facebook Page, and WhatsApp. The questionnaire was filled out by the participants on a self-administered basis. The questionnaire was divided into five sections, involving two sections consisting of multiple response options. They had to complete the socio-demographic details (i.e. age, gender, marital status, educational qualification, and occupation) as well as a young adult's perception regarding symptoms and mode of transmission of COVID-19, sources of information, preventive measures with regard to COVID-19, and experience of COVID-19 and its impact on daily life. The validity of the content was tested by a group of proficient researchers. Privacy and confidentiality were maintained in all aspects of the collection of data.

\section{Qualitative interview outline and data collection procedure (phase II)}

The snowball sampling technique was applied to collect data from 20 young adults, living in urban localities. Data were collected through an in-depth interview (IDI) process and this was continued until it reached its saturation point. A qualitative interview outline was developed by checking relevant literature, cross-checking the questionnaire by experts, and pre-testing the questionnaire before collecting the formal IDI data. The IDI questionnaires were as follows: (i) "What were your experience and insights regarding your illness condition and COVID-19 positive patients for the last few months?", (ii) "How can COVID-19 be transmitted?", (iii) "Which sources did you search most to get information about the COVID-19 pandemic and why?", (iv) "What were the psychological feelings when you came to know about a COVID-19-positive patient in your relatives?", (v) "How is COVID-19 impacting on your daily life?", (vi) "What do you think about the reasons for the rapid spread of COVID-19 in Bangladesh?", (vii) "Tell me about the preventive measures and level of satisfaction which can be taken for combating COVID-19 transmission?", etc. and lastly, (viii) participants were asked, "Give some recommendations to effectively deal with the COVID-19 situation in Bangladesh". Each interview took about 30-40 min, together with an audio recording which was performed by taking their consent, and extensive notes for each interview were made by the researchers during the data collection process.

In this current study, data were collected both in the respondent's native language and converted then into English for analysis. The meaning of the language was reviewed to ensure correctness, and cross-checked by expert linguists.

\section{Credibility}

To maintain the trustworthiness of this current study, credibility was ensured by being certain that every respondent was able to understand the questionnaire, as well as by agreeing upon what the researchers wrote down during the period of IDI sessions.

\section{Data analysis}

In phase I (the quantitative part), the Statistical Package of Social Sciences (SPSS) version 23.0 was used for data analysis. Descriptive statistics have been applied to analyze the quantitative data findings, and all categorical variables were compared using the chi-square test. The association of variables was considered significant when the $p$-value was less than or equal to 0.05 . In phase II (the qualitative part), verbatim transcriptions were performed by professional transcribers once the interviews had been finished. The transcripts were subsequently read carefully and minutely. After that, the transcripts were matched with the audio records to track out the missing information. The thematic analysis of texts was summarized, extracted, and formulated using manual coding.

\section{Results}

\section{Demographic characteristics of the participants}

For quantitative analysis, a total of 315 participants were included in this study, and the majority were in the age group of 26-30 years (32.4\%), with a mean age of 26.54 (SD: 3.05). The majority of the participants were male $(54.9 \%)$ and unmarried $(59.4 \%)$. Of them, $43.5 \%$ were undergraduate, and $17.5 \%$ were post-graduate and above. Among the participants, $43.2 \%$ were students, and $27.9 \%$ were employed. Details of the demographic characteristics of the participants were illustrated in Table 1. For qualitative analysis, 20 IDIs were conducted, and detailed information of participants included in the IDI is shown in Table 2.

\section{Perceived COVID-19 and its symptoms by study participants}

The majority of the participants (81.6\%) reported COVID-19 as a viral disease. Only a few (18.4\%) stated COVID-19 as a bacterial disease. Interestingly, participants' perception with regard to COVID-19 as viral disease was statistically different in terms of gender $\left(77.5 \%\right.$ male vs $86.6 \%$ female; $\chi^{2}=4.36$; $p<0.05$; Table 3 ). According to the male participants, they are perfectly healthy, and adults and older are the most prone to this disease; and aged patients who had already other disease ailments such as stroke, hypertension, and other related diseases could be more susceptible to have symptoms of COVID-19, as exemplified below:

"A woman aged 50 was suffering from breathing problems and cancer as well as being exposed to this virus." [IDI-4; female; age: 19 years old]. 
Table 1 Demographic characteristics of the participants $(N=315)$

\begin{tabular}{lll}
\hline Characteristic & Frequency $(n)$ & Percentage $(\%)$ \\
\hline Age (years) & & \\
$\quad$ Less than or equal to 20 & 40 & 12.7 \\
$21-25$ & 83 & 26.3 \\
$26-30$ & 102 & 32.4 \\
More than 30 & 90 & 28.6 \\
Mean \pm SD & $26.54 \pm 3.05$ & \\
Gender & & \\
Male & 173 & 54.9 \\
Female & 142 & 45.1 \\
Marital status & & \\
Unmarried & 187 & 59.4 \\
Married & 128 & 40.6 \\
Education level & & \\
Under graduation & 137 & 43.5 \\
Higher secondary & 94 & 29.8 \\
Post-graduation and above & 55 & 17.5 \\
Secondary and below & 29 & 9.2 \\
Occupation & & \\
Student & 136 & 43.2 \\
Employed & 88 & 27.9 \\
Unemployed & 53 & 10.8 \\
Business & 34 & \\
Others & & \\
\hline
\end{tabular}

${ }^{\mathrm{a}}$ doctors, teachers

When asked about common symptoms, participants reported fever $(90.8 \%)$, respiratory symptoms $(87.9 \%)$, dry cough $(85.1 \%)$, weakness $(65.1 \%)$, diarrhea $(55.9 \%)$, and headache (49.5\%). Significant differences in perception with regard to common symptoms was found between males and females in terms of fever $(86.7 \%$ male vs $95.8 \%$ female; $\chi 2=7.67$; $p<0.01)$ and respiratory symptoms $(83.8 \%$ male vs $93.0 \%$ female; $\chi^{2}=6.15 ; p<0.05$; Table 3 ).

\section{Perceptions concerning the mode of transmission of COVID-19}

The majority of the participants $(86.3 \%)$ knew the risk of going out of the house during this COVID-19 pandemic, and only a few (13.7\%) did not know about this risk. When participants were asked if COVID-19 can be spread through coming into contact with another infected person, the majority of participants (90.8\%) positively responded to this question. But a noticeable lack of perception was found among participants in response to statements such as COVID-19 can be spread from pet animals (48.6\%). A statistically significant difference was found between male and female participants

in terms of perception about the transmission of COVID-19 by going out of the house $(82.7 \%$ male vs $90.8 \%$ female; $\chi 2=4.43 ; p<0.05)$ and coming into contact with another infected person ( $87.9 \%$ male vs $94.4 \%$ female; $\chi 2=3.95 ; p$ $<0.05$; Table 3).

The majority of the study participants reported that COVID-19 can be spread through droplets of sneezing and coughing when a person is in close contact with another person. Several mentioned other options on how this disease is transmitted, i.e. it can be spread if someone touches contaminated objects and surfaces, as exemplified below:

"A person can be contaminated by touching heavy metals or polythene. If the contaminated person does not use a face mask or gloves, people around them will catch this disease." [IDI-14; male; age: 32 years old].

Other participants reported frequent visits to outside and money transactions as a mode of transmission of this disease. A day laborer living in Narayanganj, Dhaka described how he perceived COVID-19 and its mode of transmission as exemplified below: to here

"I am a day laborer; I do not know much about this disease. I have heard about this disease from television and my shop owner occasionally. I have heard that it is an illness, living in our throat. which can penetrate our body through the nose." [IDI-19; male; age: 32 years old].

Table 2 Detailed information of participants included in IDI $(N=20)$ 
Table 3 Participant's perception regarding mode of transmission, and symptoms of COVID-19 $(N=315)$

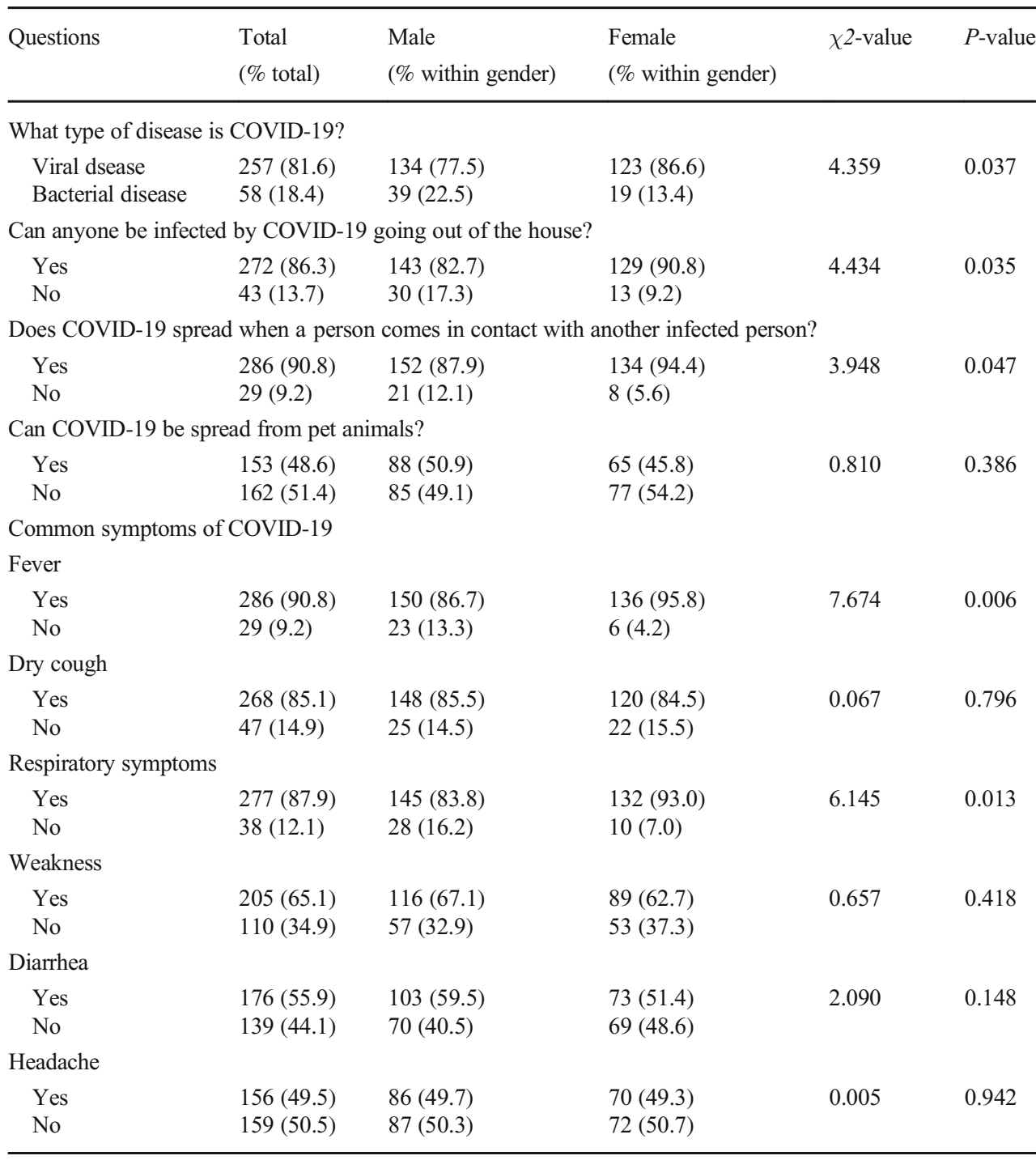

$\chi^{2}=$ Chi-square

$p \leq 0.05$ set as statistically significant

\section{Commonly used and preferred sources in seeking information regarding COVID-19 among study participants}

Most of the study participants (35.6\%) knew about COVID19 for the first time from social media (e.g., Facebook, WhatsApp), which was the most common source of information related to COVID-19, followed by different news channels $(25.1 \%)$, newspapers $(22.9 \%)$, government or healthrelated organizations' websites (8.6\%), and family and friends (7.8\%; Fig. 1). However, when asked about reliable sources, $40 \%$ of participants believed news channels as the most reliable information source. The majority of respondents said they trusted different news channels $(40.0 \%)$ and government or health-related organizations' websites $(30.2 \%)$ for reliable COVID-19 information. Interestingly, only $10.2 \%$ of participants perceived social media (e.g., Facebook, WhatsApp) as a reliable source of information related to COVID-19 (Fig. 2). However, when a young woman was asked about her preferences in seeking information on COVID-19, she described why social media would be only the best option in searching information on this matter as illustrated below:

"I search and spend most of the time on social media. I think the information provided here is the most reliable." [IDI-2; female; age: 25 years old].

\section{Perceptions regarding the preventive way to combat COVID-19}

In Table 4, when asked about preventive measures of COVID19 almost all the participants (94.9\%) clearly stated that 
Where did you first know about COVID-19?

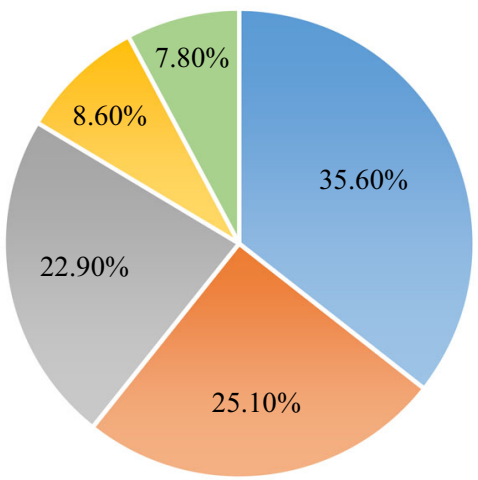

- Social media (e.g., Facebook, WhatsApp)

- News channels

" Newspapers

- Government or health-related organizations' websites

- $\quad$ Family and friends

Fig. 1 Sources of information regarding COVID-19 among the participants $(N=315)$

everybody should wear some type of mask when going outside their home. A high majority of participants also showed better perception about washing hands with soap or sanitizer (87.6\%), maintaining social distance (80.6\%) in dealing with COVID-19, although they are not clear about what distance should be maintained. When participants were asked if home quarantine or isolation was effective in preventing this disease, a significant percentage (84.4\%) of participants agreed by responding positively. Pearson correlation analysis also found that participants' perception was significantly different according to gender in terms of hand-washing ( $83.8 \%$ male vs $92.3 \%$ female; $\left.\chi^{2}=5.123 .98 ; p<0.05\right)$ and maintaining social distance $(72.8 \%$ male vs $90.1 \%$ female; $\chi 2=14.96$; $p<0.001$; Table 4).

According to the majority of the participants, those who are staying at home, maintaining lockdown rules, should follow the rules to combat COVID-19 as they did earlier.

\section{Exposure to COVID-19 patients in their locality, rela- tives, and participants' experiences}

Participants' experiences with regard to COVID-19 are shown in Table 5. From the table, $68 \%$ of participants reported having a person infected with COVID-19 in their area. The majority of the study participants came to know about COVID19 patients in their locality through hearing from other neighbors and relatives or communicating with them via telephone. Others reported that they first learned about the presence of a COVID-19 positive patient in their locality from visiting the government websites. Social media and different television channels were some other options.

"We even did not know that the person was COVID-19 positive. We saw him a few weeks ago and had a conversation with him. Even he did not tell us about his disease. Through using Facebook we learned that that person was infected with COVID-19 in our locality" [IDI-2; female; age: 25 years old].

Apart from this, only $21.6 \%$ reported that they had no exposure to COVID-19 patients in their locality. Others (10.5\%) reported that they were not sure about whether there were any COVID-19 patients in their locality. When participants were asked about whether their relatives had had that sort of disease experience or not, $32.7 \%$ of them said that their relatives were infected with COVID-19 (Table 5).
Fig. 2 Most reliable sources of information regarding COVID-19 among the participants $(N=315)$

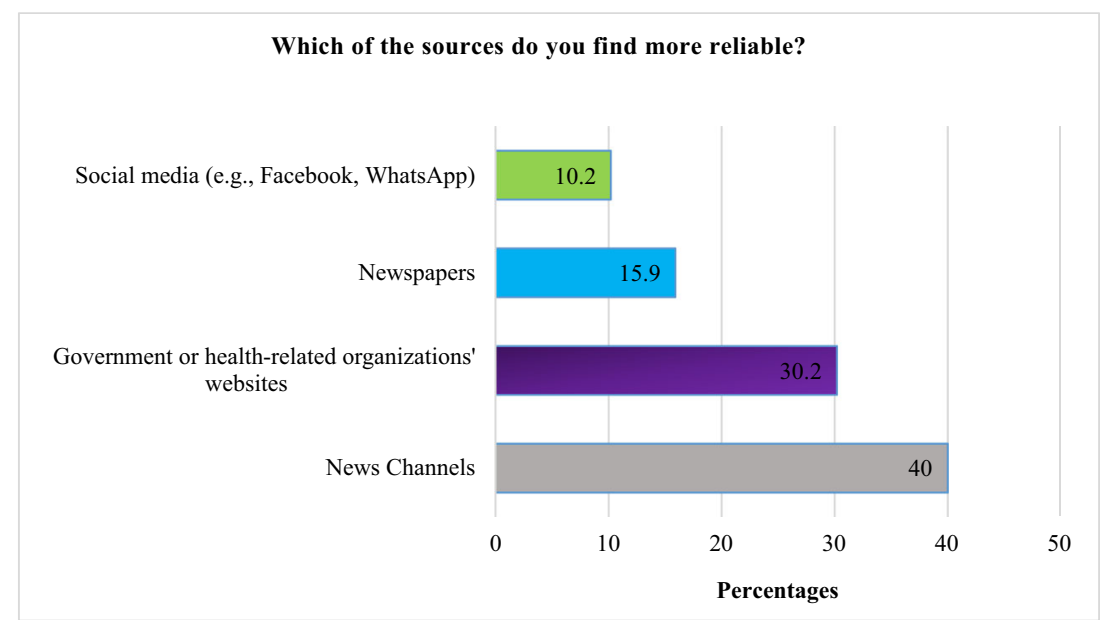


Table 4 Perception regarding preventive measures towards COVID-19 among participants and their level of satisfaction $(N=$ 315)

\begin{tabular}{|c|c|c|c|c|c|}
\hline Questions & Total $(\%$ total $)$ & Male (\% within gender) & Female ( $\%$ within gender) & $\chi^{2-\text { value }}$ & $P$-value \\
\hline \multicolumn{6}{|c|}{ Should everybody wear a mask when going outside from home? } \\
\hline Yes & $299(94.9)$ & $166(96.0)$ & $133(93.7)$ & \multirow[t]{2}{*}{0.850} & \multirow[t]{2}{*}{0.357} \\
\hline No & $16(5.1)$ & $7(4.0)$ & $9(6.3)$ & & \\
\hline \multicolumn{6}{|c|}{ Is washing hands with soap or sanitizer is one of the ways to deal with COVID-19? } \\
\hline Yes & $276(87.6)$ & $145(83.8)$ & $131(92.3)$ & \multirow[t]{2}{*}{5.119} & \multirow[t]{2}{*}{0.024} \\
\hline No & $39(12.4)$ & $28(16.2)$ & $11(7.7)$ & & \\
\hline \multicolumn{6}{|c|}{ Should social distance be maintained in dealing with COVID-19? } \\
\hline Yes & $254(80.6)$ & $126(72.8)$ & $128(90.1)$ & \multirow[t]{2}{*}{14.962} & \multirow[t]{2}{*}{0.000} \\
\hline No & $61(19.4)$ & $47(27.2)$ & $14(9.9)$ & & \\
\hline \multicolumn{6}{|c|}{ Is home quarantine or isolation effective in preventing this disease? } \\
\hline Yes & $226(84.4)$ & $151(87.3)$ & $115(81.0)$ & \multirow[t]{2}{*}{2.354} & \multirow[t]{2}{*}{0.125} \\
\hline No & $49(15.6)$ & $22(44.9)$ & $27(19.0)$ & & \\
\hline \multicolumn{6}{|c|}{ Are you satisfied with the services that have been provided so far to combat COVID-19? } \\
\hline Yes & $145(46.0)$ & $69(39.9)$ & $76(53.5)$ & \multirow[t]{2}{*}{5.838} & \multirow[t]{2}{*}{0.016} \\
\hline No & $170(54.0)$ & $104(60.1)$ & $66(46.5)$ & & \\
\hline
\end{tabular}

\section{Participants' daily life impact due to COVID-19}

When participants were asked about the impact of COVID-19, the majority (91.4\%) of the participants reported that COVID-19 is impacting every sphere of their daily life in many ways (Table 5). Employed personnel was facing problems getting their salary due to lockdown. As a result, the majority of the respondents' families were going through a crisis of basic requirements, e.g. financial crisis, collection of food, providing education to children, etc.

"I am facing financial hardship due to the shutting down of my workplace and not getting a salary" [IDI-9; female; age: 25 years old].

Table 5 Participants' experience regarding COVID-19 and its impact on daily life $(\mathrm{N}=315)$

\begin{tabular}{lcc}
\hline Questions & Frequency $(n)$ & Percentage $(\%)$ \\
\hline \multicolumn{2}{l}{ Has anyone in your area been infected } & with COVID-19? \\
Yes & 214 & 68.0 \\
No & 68 & 21.6 \\
Not sure & 33 & 10.5 \\
Have any of your relatives been infected with COVID-19? \\
Yes & 103 & 32.7 \\
No & 212 & 67.3 \\
Has COVID-19 affected your daily life? & \\
Yes & 288 & 91.4 \\
No & 27 & 8.6 \\
\hline
\end{tabular}

COVID-19 was perceived as a type of both symptomatic and asymptomatic syndrome. Surrounding this, tension, anxiety, and mental instability was reported by the majority of the respondents when they were asked about their mental situation in this moment of crisis.

"I am scared about this disease, as we do not know what type of disease this is. What are the actual symptoms? Will we be alive? If yes, for how many days? Is my family secured? I do not know. There is actually no treatment of this disease to date." [IDI-03; male; age: 29 years old].

They also thought that they could not actually get other treatments even though there are some commonalities in the symptoms of other ailments, e.g., the symptoms of dengue and COVID-19 are quite similar. As a result, they were afraid of not getting proper treatment due to COVID-19, which created an impact on their mental health.

"We cannot even talk to doctors about our problems as the doctors may misunderstand us and treat us as a COVID-19 positive patient, which creates mental fatigue." [IDI-14; male; age: 32 years old].

\section{Reasons for COVID-19 spreading in the country}

From IDIs it was found that lack of awareness among people, in general, was the main cause of transmission of the disease in their locality compared to other countries and their locality, 
as reported by the majority of the participants. One of the study participants expressed his view in this way:

"We got sufficient time from December till March, but people, in general, were not aware and have not taken preventive measures to date." [IDI-20; male; age: 20 years old].

Others reported some major issues, i.e. access to our country to people from other countries without corona testing and quarantine facilities, lack of testing facilities as well as lack of proper knowledge about this coronavirus, being in a country more densely populated than other countries, the lack of a role being played by the local administration, and so on.

\section{Participants' level of satisfaction with the health services to combat COVID-19, and recommendations}

Hearing from news media and other sources, the majority of the study participants conveyed that they were not satisfied with the existing health care services and treatments are given to COVID-19 patients. A participant expressed her level of satisfaction as illustrated below:

"We are not satisfied with the providing of services for preventing or managing the COVID-19 pandemic because going to the hospital is the main challenge now. Indeed, we see on the media channel that doctors don't treat patients properly and avoid giving them proper treatment, as well as showing rough behavior towards the patients and sometimes refusing to give treatment.”[IDI-10; female; age: 28 years old].

It was very frustrating that only $46 \%$ of participants were satisfied with the services that have been provided so far to combat COVID-19. Participants' satisfaction level with services provided by the government also showed significant differences and was higher among females than male participants (39.9\% male vs $53.5 \%$ female; $\chi 2=5.84 ; p<0.05$; Table 4 ).

Almost all the participants recommended some effective approaches to deal with the COVID-19 outbreak in Bangladesh. Further, implementation of a widespread testing facility and E-health service was highly recommended by the majority of the study participants for accessing all information and services on COVID-19.

"The more we test for COVID-19, the more we will come to know and become aware of the disease, which will create a significant pathway to taking appropriate measures to combat this disease". "E-health service could be used more so that people can at least get their health treatment" [IDI-14; male; age: 32 years old, and IDI-13; male; age: 28 years old].

\section{Discussion}

The present study evaluated perception and experiences regarding COVID-19 among urban young adults in Bangladesh. It revealed that the majority of the young adults in Bangladesh have a good perception with regard to the fact that COVID-19 is a viral disease and female participants had a comparatively better perception than males. Recent knowledge, attitude, and practices (KAP) studies in Bangladesh also found that females were more knowledgeable than males with regard to all aspects of COVID-19 (Banik et al. 2020; Wadood et al. 2020), which corresponds to the present study. Similar findings were also found in some studies among Chinese and Malaysian people (Azlan et al. 2020; Zhong et al. 2020).

The present study also found that participants were exceptionally highly aware of the common symptoms of COVID19. Almost $90 \%$ of the participants reported fever as a prime symptom, followed by respiratory symptoms and dry cough, weakness, etc. as the common symptoms of COVID-19, which is supported by a previous study in Bangladesh (Wadood et al. 2020). Some of these symptoms were similar to the Centers for Disease Control and Prevention (CDC) report on the common symptoms, including fever, cough, and shortness of breath are the major symptoms (Centers for Disease Control and Prevention 2020). This is a clear indication of incongruity in perceiving COVID-19 symptoms among study participants. Participants also perceived that young adults were at lower risk of infection and fatality due to COVID-19 compared to elder people who already had other chronic diseases such as hypertension, diabetes, heart disease, and cancer, which corresponds to a previous COVID-19 study in China (Tian et al. 2020). The majority of young adults strongly perceive this thinking but are still showing negligence with regard to the severity of COVID-19. This finding revealed an important aspect of the COVID-19 situation in Bangladesh by disclosing the underlying factors of high infectivity among people aged 18-40 years (WHO 2020b).

Regarding modes of transmission of COVID-19, most of the participants perceived that going out from home and wandering (86.3\%) and exposing to a COVID-19 positive patient (90.8\%) increasing the risk of getting infected with COVID19 , which is comparable with the previous study in Bangladesh (Farhana 2020). However, during an in-depth interview, some of the participants mentioned important sources of COVID-19 transmission such as respiratory droplets (e.g., coughing, sneezing), being close to an infected person (less than 3 feet), money exchange, and others. A study in Egypt showed that about three-quarters of participants were willing to be isolated at home and that a lower proportion was willing to stay in the hospital with a concern of if they contacted a case infected with the coronavirus (Abdelhafiz et al. 2020). Interestingly, participants also have some misconceptions, such as that COVID-19 can be transmitted through air or pet 
animals. Another study in Ethiopia reported that about $48.2 \%$ of participants thought that contact with wild animals would result in infection by the coronavirus (Kebede et al. 2020).

More than three-fifths of the participants $(68 \%)$ confirmed having COVID-19 patients in their area, either by hearing about it from neighbors and relatives or through the announcement of lockdown by the authorities. Some other participants knew about the facts by visiting government websites or social media (e.g., Facebook, WhatsApp, etc.) and different television channels. Recent studies in Bangladesh also found that the main source of primary information among participants about COVID-19 was through social media (Farhana 2020; Karim et al. 2020). Interestingly, in terms of trustworthiness, two-fifths of participants believed news channels to be the most reliable source due to the validity of their news on COVID-19. This finding is contradicted by similar studies that found social media was seen as a reliable source of seeking information regarding COVID-19 (Erfani et al. 2020; Farhana 2020).

In terms of preventive ways towards COVID-19, the majority of the participants had good perceptions and mentioned wearing a mask when going outside from home, washing hands with soap or sanitizer, and maintaining social distance as the major preventive practices with regard to COVID-19. WHO also reported that the pre-eminent way to prevent and minimize transmission in the coronavirus outbreak included general awareness among people that they should wash their hands properly with soap, use hand sanitizers frequently and carefully, avoid touching the face, nose, mouth, and eyes with unclean or unwashed hands, staying in their home and maintaining social distance to remain protected from the coronavirus infection (WHO 2020c). Other evidence also mentioned the significance of wearing various types of masks for effective infection prevention, when going outside (McFadden et al. 2020; Zhong et al. 2020). In this study also, the majority of the participants (about $84.4 \%$ ) believed that home quarantine or isolation can be effective in preventing this disease; the rest of the participants (15.6\%) did not agree. Although having a good perception of preventive practices regarding COVID19 , young adults do not sufficiently follow preventive practices. Evidence from news media showed authorities including military forces are still struggling to ensure social distancing to control the COVID-19 pandemic that has already spread across the country (Mahmud and Rashid 2020).

In this study, about $91.4 \%$ of participants stated that coronavirus affected every sphere of their daily life in terms of their financial condition, food supply, coming to terms with an acute and chronic disease condition, and psychological status. According to the United Nations (UN), the coronavirus may leave up to 25 million more people out of jobs across the world. And this will dramatically slash global workers' incomes (Khaled 2020). People in Bangladesh are also facing similar financial challenges, and those who are involved in the private sector and the garments sector are facing these hardships and have been left jobless or laid off. The situation was more critical for the people relying on daily earnings who were left without any income, which has created a public health crisis in Bangladesh. Another important factor mentioned by the participants was that due to some misconceptions, doctors often suspect patients with seasonal flu-like symptoms to have COVID-19, which creates harassment and psychological stress among the patients. They are experiencing uncertainty about the magnitude of the pandemic and how to deal with it effectively. In addition to this, epidemiological features, rapid transmission patterns, novelty, and severity of public health can result in psychological disorders such as depression, anxiety, and traumatic stress (Xiao 2020; Zandifar and Badrfam 2020).

With regard to the underlying reasons for the rapid spread of COVID-19 in Bangladesh, the majority of participants thought that lack of awareness, lack of testing, and quarantine facilities compared with other countries, religious normativity, and lack of integration of the local administration were the main reasons for rapid COVID-19 transmission. As of July 6, 2020, out of 73 laboratories in Bangladesh, 39 laboratories are situated in Dhaka. Up to the date of our study, the overall COVID-19 test rate in Bangladesh was 5096 per $1,000,000$ population, which is a markedly insufficient figure and lower than other Western countries or even the other south-east Asian countries (WHO 2020d). Furthermore, there is an absence of sufficient equipment such as testing kits, surgical gloves, and PPE for healthcare staff to address the anticipated surge in COVID-19 cases. Some social and religious normativity and stigma among young adults in Bangladesh is also being perceived and practiced with regard to COVID-19, which includes discriminatory behaviors against people of a certain class, religious group, gender, or ethnic background, as well as anyone perceived to have been in contact with the virus. All of these above-mentioned factors are aggravating the COVID-19 situation in Bangladesh. Less than half of the participants (46\%) were satisfied with the services provided or initiatives are taken by the government to date. People are very dissatisfied with the attitudes of the doctors when seeking care, which is true in terms of both COVID-19 and general patients. Participants think that a comprehensive E-Health service together with widespread testing facilities and public awareness could improve the COVID-19 situation in Bangladesh.

\section{Conclusion}

In essence, findings from this study revealed that the majority of the urban young adults in Bangladesh have a good understanding of COVID-19, although females overall had better perceptions than males. Despite this level of understanding 
about different aspects of COVID-19 such as mode of transmission, symptoms, and preventive practices, COVID-19 transmission is relatively high among young adults in Bangladesh, which indicates a level of negligence among them with regard to preventive practices. Furthermore, the majority of the participants had an anxious and worrying experience of COVID-19, which negatively affects their day-today life. Therefore, immediate implementation of health education, barrier-specific counseling and outreach, and community-based interventions should be undertaken to identify vulnerable population groups, especially the young adults, as they are contributing to the national population dividend which can further help in improving perception and preventive practices towards COVID-19 among them, and also help and counsel others to achieve this perspective.

Acknowledgments The authors are grateful to all the participants who voluntarily offered their time and conscientiously provided honest and thoughtful responses, and the personnel who supported field implementation and data collection of this study. Furthermore, they are also thankful to Arfina Akhter Keya, Fatema Tuz Zohra, and Safa Akter Ruma for collecting data online.

Authors' contribution $S P$ : conceptualization, investigation, analysis, writing - original draft, validation; $S N$ : supervision, investigation, analysis, writing - original draft, editing, validation; MURP: investigation, data curation, writing - original draft, validation; $R B$ : investigation, methodology, data curation, formal analysis, writing - original draft, validation; $Q M R$ : investigation, methodology, writing — original draft; validation.

Funding This research received no specific grant from any funding agency, commercial entity, or not-for-profit organization.

\section{Declarations}

Ethical approval This research was conducted in accordance with the guidelines of the Biosafety, Biosecurity, and Ethical Clearance Committee of Jahangirnagar University, Savar, Dhaka-1342, Bangladesh.

Informed consent All participants provided their informed consent to participate in the study after being informed about the purpose of the study.

Competing interests The authors have no competing interests to declare.

\section{References}

Abdelhafiz AS, Mohammed Z, Ibrahim ME et al (2020) Knowledge, perceptions, and attitude of Egyptians towards the novel coronavirus disease (COVID-19). J Community Health 45(5):881-890. https:// doi.org/10.1007/s10900-020-00827-7

Azlan AA, Hamzah MR, Sern TJ et al (2020) Public knowledge, attitudes and practices towards COVID-19: a cross-sectional study in
Malaysia. PLoS One 15:e0233668. https://doi.org/10.1371/journal. pone. 0233668

Banik R, Rahman M, Sikder MT, Gozal D (2020) COVID-19 in Bangladesh: public awareness and insufficient health facilities remain key challenges. Public Health 183:50-51. https://doi.org/10. 1016/j.puhe.2020.04.037

Banik R, Rahman M, Sikder MT et al (2021) Knowledge, attitudes, and practices related to the COVID-19 pandemic among Bangladeshi youth: a web-based cross-sectional analysis. J Public Health. https://doi.org/10.1007/s10389-020-01432-7

Centers for Disease Control and Prevention (CDC) (2020) Symptoms of coronavirus. Centers for Disease Control and Prevention, Atlanta, GA. https://www.cdc.gov/coronavirus/2019-ncov/symptomstesting/symptoms.html. Accessed 14 Jul 2020

Corona Tracker (2020) Bangladesh Overview. https://www. coronatracker.com/country/bangladesh/. Accessed 25 Aug 2020

Erfani A, Shahriarirad R, Ranjbar K, Mirahmadizadeh A, Moghadami M (2020) Knowledge, attitude and practice toward the novel coronavirus (COVID-19) outbreak: a population-based survey in Iran. Bull World Health Organ. https://doi.org/10.2471/BLT.20.251561

Farhana K (2020) Knowledge and perception towards novel coronavirus (COVID-19) in Bangladesh. Int Res J Bus Soc Sci 6:76-79. https:// doi.org/10.2139/ssrn.3578477

Gilbert T (2006) Mixed methods and mixed methodologies: the practical, the technical and the political. J Res Nurs 11:205-217. https://doi. org/10.1177/1744987106064634

Gudi SK, Undela K, Venkataraman R et al (2020) Knowledge and beliefs towards universal safety precautions to flatten the curve during novel coronavirus disease (nCOVID-19) pandemic among general public in India: explorations from a National Perspective. medRxiv. https://doi.org/10.1101/2020.03.31.20047126

Hossain MA, Hossain KMA, Walton LM et al (2020) Knowledge, attitudes, and fear of COVID-19 during the Rapid Rise Period in Bangladesh. PLoS One 15:e0239646. https://doi.org/10.1371/ journal.pone. 0239646

Huang C, Wang Y, Li X et al (2020) Clinical features of patients infected with 2019 novel coronavirus in Wuhan, China. Lancet 395:497506. https://doi.org/10.1016/S0140-6736(20)30183-5

Institute of Epidemiology Disease Control and Research (IEDCR) (2020) Covid-19 Status for Bangladesh. IEDCR, Dhaka. https://www. iedcr.gov.bd/. Accessed 4 Aug 2020

Islam S, Emran GI, Rahman E, et al (2020) Knowledge, attitudes and practices associated with the COVID-19 among slum dwellers resided in Dhaka City : a Bangladeshi interview-based survey. J Public Health 43(1):13-25. https://doi.org/10.1093/pubmed/ fdaa 182

Karim A, Akter M, Mazid AT et al (2020) Title: knowledge and attitude towards COVID-19 in Bangladesh: population-level estimation and a comparison of data obtained by phone and online survey methods short. medRxiv. https://doi.org/10.1101/2020.05.26.20104497

Kebede Y, Yitayih Y, Birhanu Z et al (2020) Knowledge, perceptions and preventive practices towards COVID-19 early in the outbreak among Jimma university medical center visitors, Southwest Ethiopia. PLoS One 15:1-15. https://doi.org/10.1371/journal.pone. 0233744

Khaled SMS (2020) Covid-19 may rob millions of jobs. Financial Express, Dhaka. https://thefinancialexpress.com.bd/views/covid19-may-rob-millions-of-jobs-1587400422. Accessed 14 Jul 2020

Mahmud I, Rashid M (2020) Infection keeps rising in Bangladesh as people defy lockdown rules. New Age (Bangladesh), Dhaka. https://www.newagebd.net/article/105144/infection-keeps-risingin-bangladesh-as-people-defy-lockdown-rules. Accessed 14 Jul 2020

McFadden SAM, Malik AA, Aguolu OG et al (2020) Perceptions of the adult US population regarding the novel coronavirus outbreak. PLoS One 15:1-6. https://doi.org/10.1371/journal.pone.0231808 
Ministry of Youth and Sports (2017) National Youth Policy 2017. Gov People's Repub Bangladesh, Dhaka. https://dyd.portal.gov.bd/sites/ default/files/files/dyd.portal.gov.bd/policies/21e565b2_252f 4f80 bfce_31a1cb33163d/Draft English Version of National Youth Policy 2017 (1).pdf. Accessed 8 Jun 2020

Polakovic G (2020) How does coronavirus affect young people's psyches? USC News. https://news.usc.edu/167275/how-doescoronavirus-affect-young-people-psyches/. Accessed 23 May 2020

Rahman A, Sathi NJ (2020) Knowledge attitude and preventive practices toward Covid-19 among Bangladeshi internet users. Electron J Gen Med 17:em245. https://doi.org/10.29333/ejgm/8223

Rahman QM, Rahman E, Aziz R et al (2020) Perceptions and barriers regarding telemedicine services among Bangladeshi young adults in the COVID-19 pandemic : a qualitative exploration. Asian J Health Sci 6:1-8. https://doi.org/10.15419/ajhs.v6i2.477

Tian S, Hu N, Lou J et al (2020) Characteristics of COVID-19 infection in Beijing. J Inf Secur 80:401-406. https://doi.org/10.1016/j.jinf.2020. 02.018

Wadood MA, Mamun A, Rafi MA et al (2020) Knowledge, attitude, practice and perception regarding COVID-19 among students in Bangladesh: survey in Rajshahi University. medRxiv. https://doi. org/10.1101/2020.04.21.20074757

Walker-Harding LR, Christie D, Joffe A et al (2017) Young adult health and well-being: a position statement of the Society for Adolescent Health and Medicine. J Adolesc Health 60:758-759. https://doi.org/ 10.1016/j.jadohealth.2017.03.021

Wang C, Horby PW, Hayden FG, Gao GF (2020) A novel coronavirus outbreak of global health concern. Lancet 395:470-473. https://doi. org/10.1016/S0140-6736(20)30185-9
World Health Organization (WHO) (2020a) Coronavirus. WHO, Geneva. https://www.who.int/health-topics/coronavirus\#tab=tab_1. Accessed 23 May 2020

World Health Organization (WHO) (2020b) COVID-19: Situation Report No. \# 15. WHO, Bangladesh

World Health Organization (WHO) (2020c) Infection prevention and control during health care when novel coronavirus $(\mathrm{nCoV})$ infection is suspected. Interim guidance. WHO, Geneva

World Health Organization (WHO) (2020d) WHO Bangladesh COVID19 Morbidity and Mortality Weekly Update. WHO, Bangladesh. https:/www.who.int/docs/default-source/searo/bangladesh/covid19-who-bangladesh-situation-reports/who-covid-19-update-1920200706.pdf?sfvrsn=94199f51_2. Accessed 14 Jul 2020

Xiao C (2020) A novel approach of consultation on 2019 novel coronavirus (COVID-19)-related psychological and mental problems: structured letter therapy. Psychiatry Investing 17:175-176. https:// doi.org/10.30773/pi.2020.0047

Zandifar A, Badrfam R (2020) Iranian mental health during the COVID19 epidemic. Asian J Psychiatry 51:101990. https://doi.org/10.1016/ j.ajp.2020.101990

Zhong BL, Luo W, Li HM et al (2020) Knowledge, attitudes, and practices towards COVID-19 among Chinese residents during the rapid rise period of the COVID-19 outbreak: a quick online crosssectional survey. Int J Biol Sci 16:1745-1752. https://doi.org/10. $7150 /$ ijbs. 45221

Publisher's note Springer Nature remains neutral with regard to jurisdictional claims in published maps and institutional affiliations. 